\title{
Influence of Arbuscular Mycorrhiza and Source of Phosphorus on Root Development and Nodulation of Acacia mangium Seedlings on Degraded Soils
}

\author{
M Abdus Satter ${ }^{1 *}$, M Musa Hanafi², Tenku MM Mahmud ${ }^{2}$ and Hashim Azizah² \\ ${ }^{1}$ Soil Science Division, Bangladesh Agricultural Research Institute (BARI), Joydebpur, Gazipur 1701, Bangladesh, ${ }^{2}$ Faculty of Agriculture, University \\ Putra Malaysia (UPM), Serdang, Selangor, Malaysia
}

[Received 08 May 2006; Accepted 07 October 2006]

\begin{abstract}
A pot study on the effect of arbuscular mycorrhiza (AM) and phosphate rock (PR) on root development and nodulation of Acacia mangium seedlings on degraded (tin tailing) soils was conducted in the glasshouse of Universiti Putra Malaysia (UPM), Malaysia. Two arbuscular mycorrhiza (AM) inoculation treatments, viz., (i) with $A M$ and (ii) without $A M$ in combination with three $P$ sources like Gafsa phosphate rock (GPR), China phosphate rock (CPR) and triple superphosphate (TSP) including a control (without P) were studied in split plot design. Six sets of this treatment combination were established for destructive sampling at $60,75,90$, 105, 120 and 135 days after planting (DAP). Root biomass yields and root volume of inoculated seedlings given TSP and GPR were identical and superior to that with other treatments throughout the study. The $P$ sources were in the order of TSP $>$ GPR $>$ CPR for enhancing root development irrespective of AM inoculation. The uninoculated seedlings required 15 to 20 more days to produce an equivalent root biomass to that of inoculated seedlings. Number and weight of nodules of AM inoculated seedlings given TSP and GPR were also higher than those with other treatments. As a cheaper source GPR in combination with AM might be used for growing $A$. mangium seedlings on degraded tin tailings.
\end{abstract}

Keywords: Acacia mangium, Arbuscular mycorrhiza, Phosphate rock, Root development, Nodulation, Degraded soil

\section{Introduction}

Highly weathered acid soils in the tropics are widely deficient in phosphorus (P). Acid soils cover most of the areas in the tropics including degraded ex-tin mining lands (tin tailings) in Malaysia. Due to inefficient utilization of soluble superphosphates by crops in these soils less soluble and less expensive phosphate rocks (PRs) have been suggested for crop production. Direct application of PRs in oil palm has been a standard practice in Malaysia since $1930 s^{1}$. The PRs from different sources differ in their physical, chemical and mineralogical properties; and hence in their solubility and availability of $\mathrm{P}$ to crop plants ${ }^{2}$. Because of such differences it is most likely that crop performance with different PR sources might also vary.

The arbuscular mycorrhiza (AM) fungi are known to improve plant uptake of immobile nutrients particularly $\mathrm{P}$ from high P-fixing soils and also from the less soluble P sources like PRs. It is therefore likely that plants infected with AM fungi can significantly benefit from PR application in these soils. Improvement of $\mathrm{P}$ nutrition helps in root development and nodulation of legumes. Acacia species depend on adequate $\mathrm{P}$ supply for good nodulation and rapid growth ${ }^{3}$. Acacia mangium has also been found to respond favourably to AM inoculation especially at low levels of soil solution $\mathrm{P}^{4}$. Mycorrhiza inoculation helps legumes increase their nodulation and thereby biological $\mathrm{N}_{2}$-fixation through improved $\mathrm{P}$ nutrition. The information suggests that application of PR in combination with AM inoculation might help in root development, nodulation and $\mathrm{N}_{2}$ fixation in A. mangium seedlings. The AM infected seedlings are also expected to perform better in the field; because the AM fungi could be carried over to the field through AM colonized roots and spores in the rhizosphere soils.

The present investigation was therefore undertaken to observe the effect of different $\mathrm{P}$ sources in combination with AM inoculation on root development and nodulation of $A$. mangium seedlings grown on degraded tin tailings.

\section{Materials and Methods}

The experiment was conducted in the glasshouse of Universiti Putra Malaysia (UPM), Malaysia in split plot design with four replications. Mycorrhiza inoculation was allocated to the main plot and P source to the sub-plot. Two AM inoculation treatments, viz., (i) with AM and (ii) without AM in combination with three $\mathrm{P}$ sources, viz., (i) GPR, (ii) CPR and (iii) TSP, and a control (without P) were studied. Six sets of this combination were established for destructive sampling at 60, 75, 90, 105, 120 and 135 days after planting (DAP). Fertilizers were used at the rate of 50-40 to 2.5-5.0

*Corresponding author:

Dr. M Abdus Satter, Principal Scientific Officer (Soil), Bangladesh Agricultural Research Council (BARC), Farmgate, Dhaka 1215, Bangladesh

Tel (Office): (02) 9132411; Cell: 0171 6420890; E-mail: satterbari@yahoo.com 
mg PKMnS and $0.32 \mathrm{~g}$ dolomite per kg soil. Sterilized (fumigated) tin-tailings ( $3.5 \mathrm{~kg} / \mathrm{pot})$ were used as the potting media. The soil was deficient in $\mathrm{P}$. The other nutrients, cation exchange capacity (CEC) and organic carbon contents were also low. The physical and chemical properties of the soil had been reported earlier ${ }^{5}$.

Acacia mangium was used as the test species. Seeds of A. mangium were treated with hot water at $80^{\circ} \mathrm{C}$ for $5 \mathrm{~min}$, soaked overnight, mixed with Rhizobium inoculum and then sown in sterilized sand. Seedlings were transplanted to the pots at 21 days after sowing (DAS). In the AM inoculated treatments, a hole of $2.5 \mathrm{~cm}$ in diameter and $6 \mathrm{~cm}$ in depth was dug at the centre of the potting media. Fifty grams of mixed AM inoculum (Glomus mossaeae, Gigaspora gigantica and Scutellospora calospora) with 165 spores/10 g soil along with mycelium and infected root pieces of the host plant (setaria grass) was placed in the hole. A 1-cm layer of soil was placed on the inoculum. The seedling was planted at the centre of the hole above the inoculum soil to ensure penetration of the roots through the inoculum. Control plants were similarly treated using steam sterilized inoculum soils. Watering and other cultural operations were done as and when necessary. The plants were harvested as per schedule mentioned earlier. Nodules were separated from the roots. Root volume was measured by water displacement method using a measuring cylinder. The roots and nodules were then oven-dried at $70^{\circ} \mathrm{C}$ to constant weight in an air-ventilated oven. Dry weight of roots and nodules were recorded separately. Data were analysed using the statistical package MSTAT-C.

\section{Results and Discussion}

\section{Root development}

Mycorrhiza inoculation and $P$ fertilization significantly influenced root development of $A$. mangium seedlings. Root biomass and root volume of AM inoculated seedlings were significantly higher (71 and $70 \%$, respectively) than that of uninoculated seedlings (Table 1). Azizah et al. ${ }^{6}$ also found better growth of three tropical forest species with AM inoculation on sandy tailings.

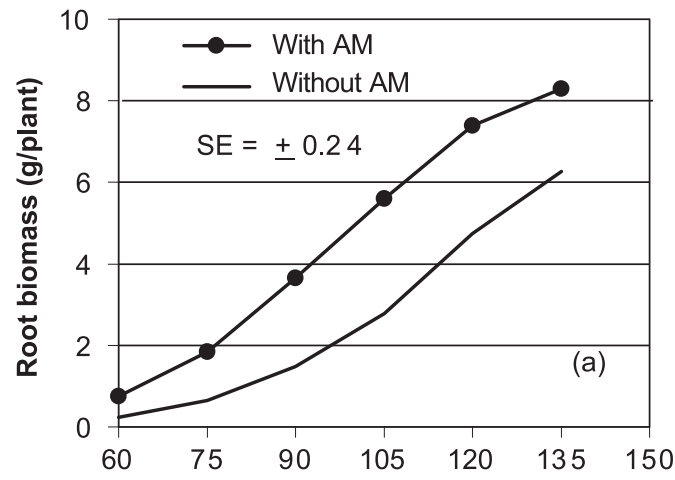

Table 1. Effect of arbuscular mycorrhiza (AM) on root and nodule variables of Acacia mangium seedlings in the glasshouse of UPM, Malaysia

\begin{tabular}{lcccc}
\hline Treatment & $\begin{array}{c}\text { Root } \\
\text { biomass } \\
\text { (g/plant) }\end{array}$ & $\begin{array}{c}\text { Root } \\
\text { volume } \\
\left(\mathrm{cm}^{3}\right)\end{array}$ & $\begin{array}{c}\text { Nodule } \\
\text { number } \\
\text { (No./plant) }\end{array}$ & $\begin{array}{c}\text { Nodule } \\
\text { weight } \\
(\mathrm{mg} / \mathrm{plant})\end{array}$ \\
\hline With AM & 4.59 & 31.43 & 109 & 123.6 \\
Without AM & 2.69 & 18.54 & 75 & 75.9 \\
F-Test & $* *$ & $* *$ & $* *$ & $* *$ \\
\hline
\end{tabular}

Interaction effect of AM and seedling age on root biomass yield and root volume was significant. Figure 1 and 2 show that root biomass and root volume of AM inoculated seedlings were significantly higher than that of uninoculated seedlings throughout the study. The uninoculated seedlings required 15 to 20 more days to produce equivalent root biomass and root volume to that of uninoculated seedlings. Interaction effect of AM and P source on root biomass yield and root volume were also significant. Root biomass yield and root volume of inoculated seedlings given TSP and GPR were identical and superior to that with other treatments. In acid soils of very low P-retention capacity the water insoluble P sources such as PR is usually of equal or superior in effectiveness to water-soluble superphosphates ${ }^{7}$. The AM fungi are known to be efficient in uptake of $\mathrm{P}$ from insoluble $\mathrm{P}$ sources like phosphate rocks ${ }^{8}$. The AM fungi can use Fe- and Al-phosphates not available to higher plants ${ }^{9}$. The $\mathrm{P}$ sources were in the order of TSP $>$ GPR $>$ CPR for enhancing production of root biomass and root volume irrespective of AM inoculation. Zaharah et al. ${ }^{1}$ also found $\mathrm{P}$ uptake by oil palm seedlings from different $\mathrm{P}$ sources in the order of TSP $>$ GPR $>C P R$. Interaction effect of $\mathrm{P}$ source and seedling age on root biomass yield and root volume was also significant. At 75 DAP, root biomass yield and root volume of the seedlings given different $\mathrm{P}$ sources were identical. From 75 DAP onwards the seedlings given TSP produced the highest biomass and root volume, which were identical to those given GPR but superior to those with other treatments throughout the study. The seedlings given TSP, GPR and CPR

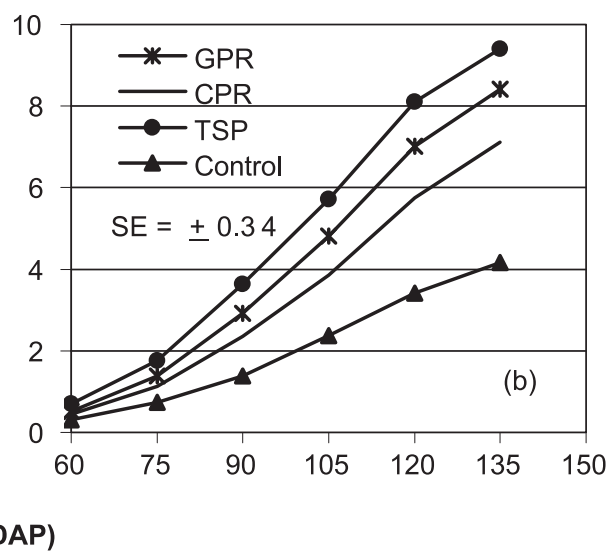

Figure 1. Effect of (a) arbuscular mycorrhiza (AM) and (b) phosphate (P) source on root biomass yield of Acacia mangium seedlings over time in the glasshouse. DAP = Days after sowing; GPR = Gafsa phosphate rock; CPR = China phosphate rock; TSP = Triple super phosphate 


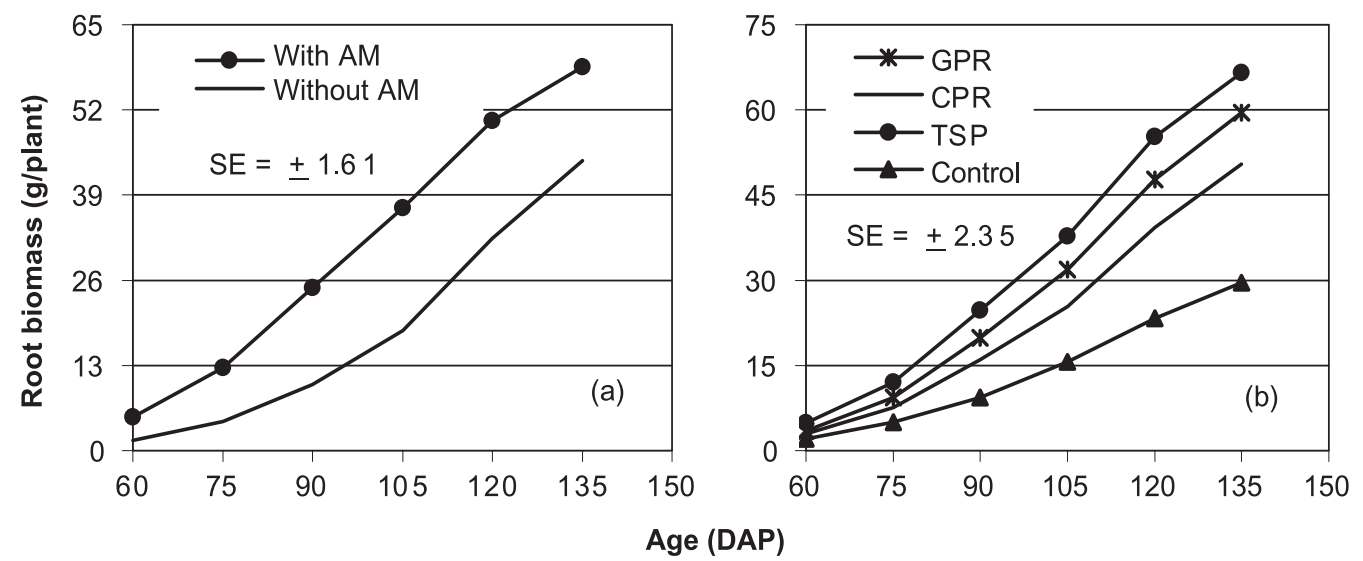

Figure 2. Effect of (a) arbuscular mycorrhiza (AM) and (b) phosphate (P) source on root volume of Acacia mangium seedlings over time in the glasshouse. $D A P=$ Days after sowing; $G P R=$ Gafsa phosphate rock; $C P R=$ China phosphate rock; TSP = Triple superphosphate

produced 2.26, 2.02 and 1.71 times higher root biomass, respectively over those of control seedlings. The increased rooting density enabled roots to explore more soil volume for better absorption of nutrients and moisture compared to the less dense roots in the other treatments.

\section{Nodule development}

Mycorrhiza inoculation and P fertilization also significantly influenced nodule development of $A$. mangium seedlings. Effect of AM on nodule number and nodule weight per plant was significant. Nodule number and nodule weight of inoculated seedlings were significantly higher than of uninoculated seedlings (Table 1). Interaction effect of AM and seedling age on nodule number was not significant but on nodule weight was significant. At 60 DAP, nodule number and weight in the inoculated and uninoculated seedlings were almost similar (Figure 3). The effect of AM became evident with increase in seedling age. From 75 DAP onwards weight of nodules of inoculated seedlings were significantly higher than that of uninoculated seedlings. Difference in nodule weight between inoculated and uninoculated seedlings increased with seedling age. The number of nodules in the inoculated seedlings was also much higher from 75 DAP onwards compared to uninoculated seedlings. Interaction effect of AM and P source on nodule number and nodule weight per plant was not significant.

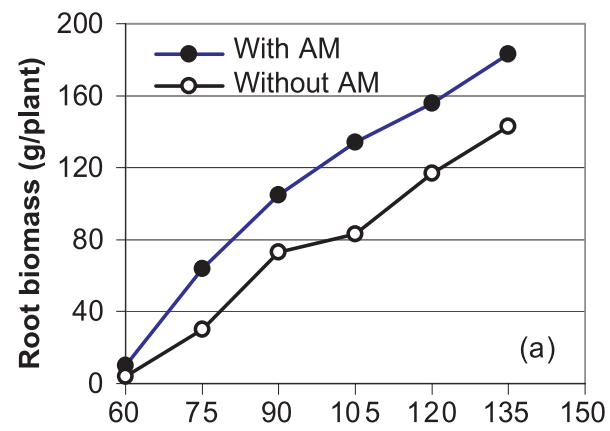

Table 2 clearly shows that inoculated seedlings produced much higher number and weight of nodules per plant compared to uninoculated seedlings, irrespective of the P sources. Inoculated seedlings given TSP, GPR, CPR and control produced 1.29, 1.68, 2.05 and 2.46 times higher weight of nodules, respectively, compared to uninoculated seedlings. There was significant variation in the number and weight among different size of nodules (Table 3). Smaller size nodules were more in numbers than bigger size nodules. Number of smaller size (grade 1 and 2) nodules per plant was significantly higher in inoculated seedlings than uninoculated seedlings, while the number of bigger size nodules (grade 3 and 4) was identical between the inoculated and uninoculated seedlings. Weight of different nodule grade of inoculated seedlings was significantly higher than the respective nodule grade from uninoculated seedlings. Bigger size and heavier nodules from mycorrhizal seedlings given TSP and GPR could probably be due to better $\mathrm{P}$ nutrition through the mycorrhizal symbiosis ${ }^{10}$. Inoculated seedlings produced significantly higher nodule weight of grade 2 compared to the other grades. Nodule pigment colour was found to vary significantly among different size grades. The pigment colour of grade 3 was significantly brighter than that of grade 1 and 2 but identical to that of grade 4 (Table 3). The lighter pigment colour in grade 1 nodules indicates that they might be less effective.

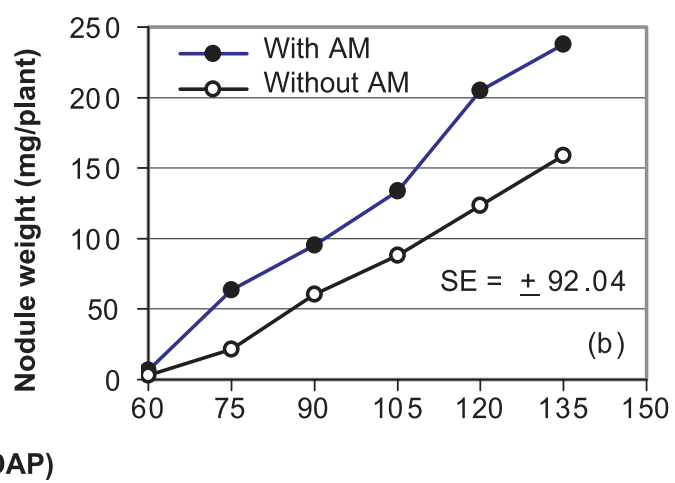

Figure 3. Interaction effect of arbuscular mycorrhiza (AM) and plant age on (a) number and (b) weight of nodules per plant of Acacia mangium. DAP = Days after sowing 
Influence of Arbuscular Mycorrhiza and Phosphorus on Acacia mangium Seedlings

Table 2. Interaction effect of arbuscular mycorrhiza (AM) and phosphate (P) source on root and nodule variables of Acacia mangium seedlings in the glasshouse of UPM, Malaysia

\begin{tabular}{|c|c|c|c|c|c|c|c|c|}
\hline \multirow[t]{2}{*}{ P source } & \multicolumn{2}{|c|}{ Root biomass (g/plant) } & \multicolumn{2}{|c|}{ Root volume $\left(\mathrm{cm}^{3}\right)$} & \multicolumn{2}{|c|}{ Nodule number (No./plant) } & \multicolumn{2}{|c|}{ Nodule weight (mg/plant) } \\
\hline & With AM & Without AM & With AM & Without AM & With AM & Without AM & With AM & Without AM \\
\hline$\overline{G P R}$ & $5.16^{\mathrm{a}}$ & $3.19^{c}$ & $35^{\mathrm{a}}$ & $22^{\mathrm{C}}$ & 104 & 92 & 141.6 & 84.5 \\
\hline TSP & $5.46^{\mathrm{a}}$ & $4.32^{b}$ & $37^{\mathrm{a}}$ & $30^{\mathrm{b}}$ & 149 & 114 & 180.0 & 139.9 \\
\hline Control & $3.26^{\mathrm{c}}$ & $0.86^{\mathrm{e}}$ & $22^{\mathrm{C}}$ & $6^{\mathrm{e}}$ & 66 & 31 & 61.0 & 24.7 \\
\hline F-Test & $* *$ & & * & & NS & & NS & \\
\hline
\end{tabular}

* = Significant; NS = Not significant; GPR = Gafsa phosphate rock; CPR = China phosphate rock; TSP = Triple superphosphate

Table 3. Effect of arbuscular mycorrhiza (AM) on nodule variables of Acacia mangium seedlings in the glasshouse

\begin{tabular}{|c|c|c|c|c|c|}
\hline \multirow[t]{2}{*}{ Nodule grade } & \multicolumn{2}{|c|}{$\begin{array}{l}\text { Nodule number } \\
\text { (No./plant) }\end{array}$} & \multicolumn{2}{|c|}{$\begin{array}{l}\text { Nodule weight } \\
\text { (mg/plant) }\end{array}$} & \multirow[t]{2}{*}{$\begin{array}{l}\text { Nodule pigment colour } \\
\qquad(0-10 \text { scale })\end{array}$} \\
\hline & With AM & Without AM & With AM & Without AM & \\
\hline $1(<2)$ & $250^{\mathrm{a}}$ & $176^{\mathrm{b}}$ & $104.5^{c}$ & $66.0^{\mathrm{d}}$ & $5.5^{c}$ \\
\hline $2(2-3)$ & $134^{\mathrm{C}}$ & $89^{d}$ & $186.2^{\mathrm{a}}$ & $102.5^{c}$ & $7.5^{\mathrm{b}}$ \\
\hline $3(3-4)$ & $44^{\mathrm{e}}$ & $31^{\mathrm{e}}$ & $149.5^{b}$ & $97.8^{\mathrm{c}}$ & $9.0^{\mathrm{a}}$ \\
\hline $4(>4)$ & $6^{f}$ & $4^{\mathrm{f}}$ & $54.2^{\mathrm{de}}$ & $37.3^{\mathrm{e}}$ & $8.1^{\mathrm{ab}}$ \\
\hline F-Test & $* *$ & & $* *$ & & $* *$ \\
\hline
\end{tabular}

* = Significant

\section{Mycorrhizal development}

Figure 4 and 5 show massive AM root colonization in A. mangium seedlings. Root colonization and spore population in the rhizosphere soils of inoculated seedlings were found significantly higher than that of uninoculated seedlings. Both the variables increased significantly with seedling age. Root colonization followed significant quadratic trend, while spore numbers significant positive linear trend with increase in seedling age (Figure 4). There was also some root colonization and spores in rhizosphere in the uninoculated seedlings as a result of colonization with the indigenous AM fungi. Interaction effect of $\mathrm{AM}$ and $\mathrm{P}$ source was significant on root colonization but was not on spore population (Figure 5). The highest root colonization and spore population was observed in the inoculated seedlings given CPR, which was identical to that also with inoculated seedlings without $\mathrm{P}$ but was superior to that with other treatments.
The external AM hyphae act as extension of root hairs. The external hyphae can extend up to several centimetres beyond the infected root surface and can increase root surface area and the absorption zone for exploration of greater soil volume for nutrient and moisture uptake ${ }^{11}$. This is particularly important for nutrients with narrow diffusion zone like $\mathrm{P}, \mathrm{Zn}$ and $\mathrm{Cu}^{12}$. The AM hyphae could intercept labelled P placed $27 \mathrm{~cm}$ apart from the mycorrhizal root, whereas it remained unavailable to non-mycorrhizal roots ${ }^{13}$. The rate of nutrient uptake by mycorrhizal roots is also faster than that by non-mycorrhizal roots ${ }^{14}$. The rate of inflow of $\mathrm{P}$ through AM hyphae is six times the rate of inflow into normal root hairs ${ }^{15}$. All these factors enabled mycorrhizal A. mangium seedlings in the present study to absorb more nutrients compared to non-mycorrhizal seedlings enhancing them to produce more root biomass. Results from this experiment is in agreement with findings by Guissou et al. ${ }^{8}$ who showed higher growth and
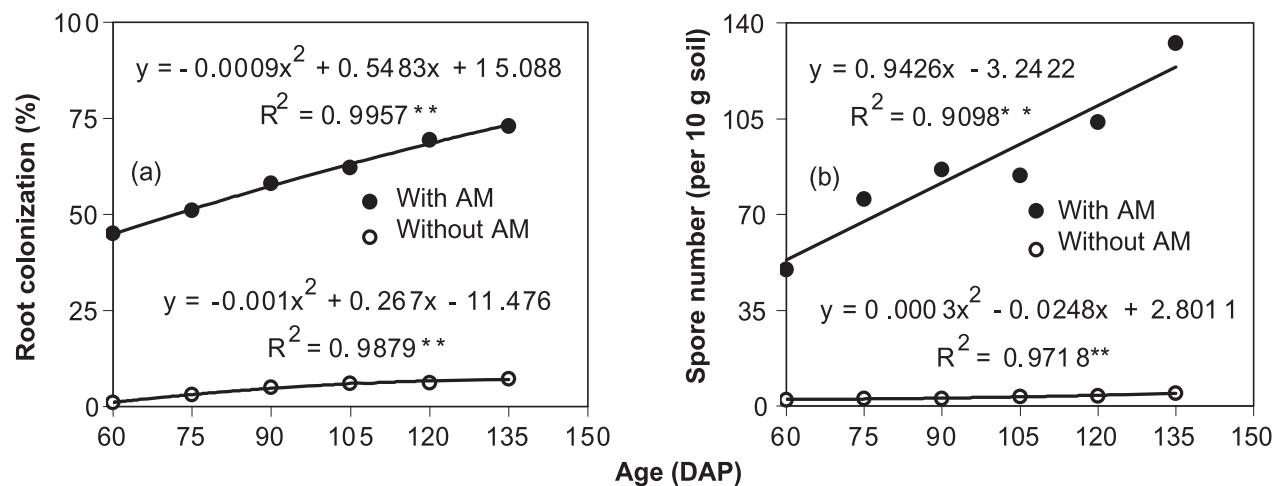

Figure 4. Interaction effect of arbuscular mycorrhiza (AM) and plant age on (a) root colonization and (b) spore number in rhizosphere soils of Acacia mangium seedlings. DAP = Days after sowing 

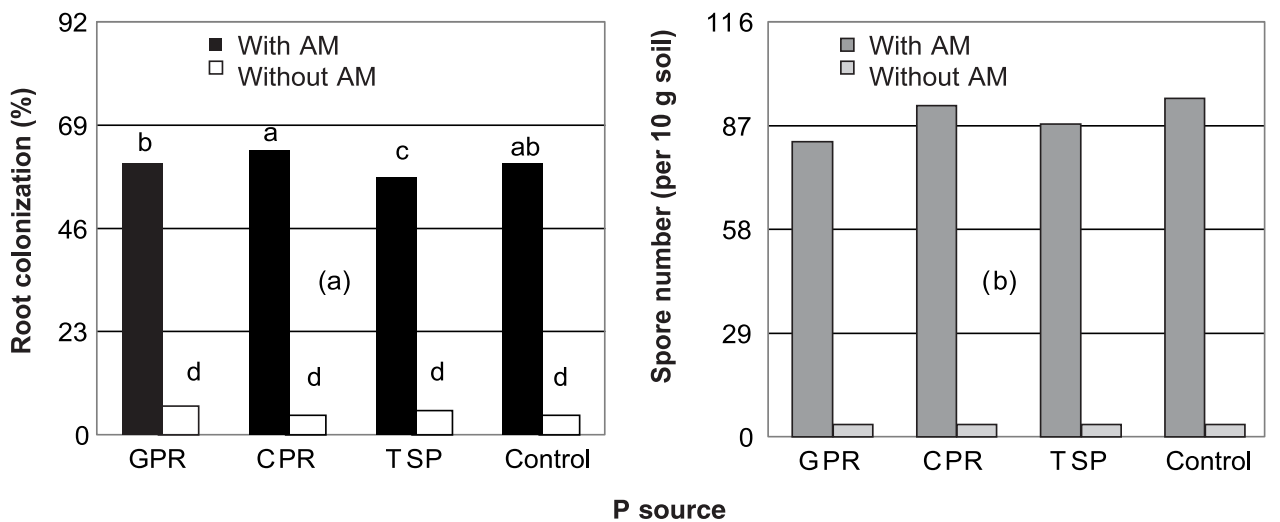

Figure 5. Interaction effect of arbuscular mycorrhiza $(A M)$ and phosphate $(P)$ source on (a) root colonization and (b) spore number in rhizosphere soils of Acacia mangium seedlings. GPR = Gafsa phosphate rock; $C P R=$ China phosphate rock; TSP = Triple superphosphate

nutrient uptake by Zizyphus mauritiana given the phosphate rock and AM inoculation.

From the results it is evident that mycorrhiza inoculation and $\mathrm{P}$ fertilization significantly influenced root development and nodulation of A. mangium seedlings. Response of A. mangium seedlings to different $\mathrm{P}$ sources was different. Root biomass yield and root volume of inoculated seedlings given TSP and GPR were identical and superior to that with other treatments throughout the study. Nodule weight of inoculated seedlings with TSP and GPR were also higher than that of uninoculated seedlings. As a cheaper source GPR in combination with AM might be used for growing $A$. mangium seedlings on degraded tin tailings.

\section{References}

1. Zaharah AR, Zulkifli H \& Sharifuddin HAH. 1997. Evaluating the efficiency of different phosphate fertilizer sources for oil palm seedlings. Nutr Cycl Agroecosyst. 47: 93-98.

2. Smyth TJ \& Sanchez PA. 1982. Phosphate rock dissolution and availability as affected by phosphorus sorption. Soil Sci Soc Am J. 46: 339-345.

3. Jasper DA, abbott LK \& Robson AD. 1989. Acacias respond to additions of phosphorus and to inoculation with VA mycorrhizal fungi in soils stockpiled during mineral sand mining. Plant Soil. 115: 99-108.

4. Habte M \& Soedarjo M. 1996. Response of Acacia mmangium to vesicular-arbuscular mycorrhizal inoculation, soil $\mathrm{pH}$ and soil $\mathrm{P}$ concentration in an oxisol. Can J Bot. 74: 155-161.

5. Satter MA, Hanafi MM, Mahmud TMM \& Azizah H. 2004. Effect of arbuscular mycorrhiza and rate of phosphorus on uptake of major nutrients by Acacia mangium seedlings on degraded soil. Bangladesh J Microbiol. 21(2): 50-54.
6. Azizah H, Rosenani AB \& Majid NM. 1994. Mycorrhiza and their role in tropical plantation forestry. Proceedings of International Workshop. BIOREFOR, Kangar, Malaysia.

7. Ballard R. 1989. Fertilization of plantations. In Nutrition of Plantation Forests (Bowen GD \& Nambiar EKS eds), pp 211-236. Academic Press, Sydney.

8. Guissou T, Ba AM, Guinko S, Duponnois R \& Plenchette C. 1999. Rock phosphate and vesicular-arbuscular mycorrhiza effects on growth and mineral nutrition of Zizyphus mauritiana Lam in an alkaline soil. Ann Sci For. 55: 925-931.

9. Jehne W \& Thompson CH. 1981. Endomycorrhizae in plant colonization on coastal sand-dunes at Cooloola, Quinsland. Aust $J$ Ecol. 6: 221-230.

10. De la Cruz RE, Manalo MQ, Aggangan NS \& Tanbalo JD. 1988. Growth of three legume trees inoculated with VA mycorrhizal fungi and Rhizobium. Plant Soil. 108: 111-115.

11. Johansen A, Jacobsen I \& Jensen ES. 1993. External hyphae of vesicular-arbuscular mycorrhizal fungi associated with Trifolium subterraneum L. 3. Hyphal transport of ${ }^{32} \mathrm{P}$ and ${ }^{15} \mathrm{~N}$. New Phytol. 124: $61-68$.

12. Marschner H \& Dell B. 1994. Nutrient uptake in mycorrhizal symbiosis. Plant Soil. 159: 89-102.

13. Hattingh MJ, Gray LE \& Gerdemann JW. 1973. Uptake and translocation of ${ }^{32} \mathrm{P}$ labelled phosphate to onion roots by endomycorrhizal fungi. Soil Sci. 116: 383-387.

14. Son CL \& Smith SE. 1988. Mycorrhizal growth responses: interaction between photon irradiance and phosphorus nutrition. New Phytol. 108: $305-314$.

15. Sanders FE \& Tinker PBH. 1973. Phosphate flow into mycorrhizal roots. Pestic Sci. 4: 385-395. 